\title{
Human Remains from Liang Nabulei Lisa, Aru Islands
}

\author{
David Bulbeck \\ School of Archaeology and Anthropology, The Australian National University, Canberra, ACT, Australia
}

\section{Introduction}

Fragments of human skeletal material were recovered from the Liang Nabulei Lisa excavation. They had already been washed and cleaned when brought to the author for study on two occasions, by Sue O'Connor in late 1997 and Juliette Pasveer on 17 May 2001. Their condition could be described as semi-fossilized, whether their appearance is unburnt (the majority) or burnt. I identified the fragments by anatomical element and sought joins between them and other evidence of the minimum number of individuals represented.

With respect to the age of the remains, O'Connor et al. (Chapter 7, this volume) detail the early Holocene age of the dated sample from Spit 23, and the predominantly terminal Pleistocene age $(16,200-10,200 \mathrm{cal} \mathrm{BP})$ for spits below Spit 25. Certain patterns in the faunal material from these spits are also interpreted to reflect the Pleistocene to Holocene transition. The observation that human remains have been buried into these spits, as documented in this paper, may indicate that the archaeological evidence for the Pleistocene-Holocene transition would be even clearer were it not for the disturbance associated with the burial of the human material. As for dating the Liang Nabulei Lisa human remains, an early Holocene estimate would seem best for the adult material distributed between Spits 23 and 39, if a single individual is in fact represented. The remains of the younger (Spits 29-35) and older child (Spits 33-36) may also be early Holocene in age, but they could equally date to the terminal Pleistocene in view of the fact that they are distributed in levels which date to the terminal Pleistocene. This interpretation is based on the fact that any burial event would have to be contemporary with, or certainly no older than, the most recent material whose disturbance might be due to the burial event. However, spits above 20 have considerable quantities of marine/estuarine shellfish and there is little or no marine/estuarine shellfish in spits below 23 . The lack of marine/estuarine shellfish in the spits where the skeletal material occurs may be taken to indicate that even the adult material was not buried from much higher in the profile than Spit 23. 
The author effected measurement of tooth diameters and cranial vault thickness with a Mitotoyu electronic calliper accurate to $0.05 \mathrm{~mm}$, and phalanx lengths were taken according to Martin's system (Martin and Saller 1957:554, 589) with a Stalon sliding calliper accurate to the nearest $0.5 \mathrm{~mm}$. Dental morphological traits were recorded in terms of the grades established by the Arizona State University (ASU) system, whenever possible with reference to the standard casts illustrating these grades of expression (Hillson 1996:85-102; Scott and Turner 1997: Chapter 2).

The fragments weigh 70.1g in all (see Table 8.1) and came from possibly four individuals: two juveniles, an older adolescent or young adult, and a mature adult. They were encountered between Spits 23 and 41, and many fragments joined across different spits, including one evident join between fragments in Spits 23 and 37, as part of a partial calvarium whose constituent parts were found in eight separate spits as far down as Spit 39 (Fig. 8.1). The depth difference between Spits 23 and 39 is about $32 \mathrm{~cm}$, which is over twice the average height of a human cranium (cf. Howells 1989:123). This is indicative of burial or post-depositional factors that led to some vertical dispersion of the human fragments in the site's deposit. A clear dichotomy emerges between the teeth, which are generally splintered and almost always show signs of having been burnt, and the bone fragments which appear unburnt except for a femur fragment from Spit 23.

Table 8.1 Liang Nabulei Lisa: distribution of human material through the sequence

\begin{tabular}{llcll}
\hline SPIT & ElEMENT & WEIGHT (G) & CONDITION & COMMENTS (REJOINS SHOWN DOWNWARDS) \\
\hline 23 & Calvarium & 2.7 & Unburnt & Rejoins with a Spit 37 fragment \\
23 & Femur & 8.2 & Well burnt & 3 rejoining fragments \\
27 & Pelvis & 2.7 & Unburnt & Same pelvis as Spit 37 fragment (?) \\
29 & Deciduous tooth & 0.2 & Burnt & 3-6 year old \\
32 & Calvarium & 0.7 & Unburnt & Rejoins with Spit 37/38 fragments \\
33 & Teeth & 1.2 & 1 burnt & Burnt tooth incorporates an enamel fragment from Spit 34 \\
33 & Manual phalanx & 0.3 & Unburnt & Fused epiphysis \\
34 & Teeth & 0.9 & Burnt & Tooth enamel fragments that rejoin with Spit 35 crown fragments \\
34 & Zygomatic arch & 0.6 & Unburnt & \\
34 & Phalanges & 3.9 & Unburnt & 4 manual + 1 pedal \\
35 & Calvarium & 2.2 & Unburnt & Rejoins with Spit 37/38 fragments \\
35 & Teeth & 1.8 & Most burnt & 1 molar cap rejoins a Spit 37 root \\
35 & Manual phalanges & 0.9 & Unburnt & \\
35 & Pelvis & 2.2 & Unburnt & \\
36 & Cranium & 1.6 & Unburnt & \\
36 & Teeth & 2.6 & Most burnt & \\
36 & Manual phalanges & 2.1 & Unburnt & Perforation from excavation damage \\
37 & Calvarium & 20.9 & Unburnt & Rejoins with Spit 38/39 fragments \\
37 & Teeth & 1.6 & Burnt & \\
37 & Pelvis & 2.3 & Unburnt & \\
38 & Calvarium & 8.0 & Unburnt & \\
39 & Calvarium & 2.6 & Fractured & Spall \\
41 & Tooth enamel & 0.1 & Fractured & \\
\hline
\end{tabular}

\section{Description of the Teeth}

Spit 29 yielded a burnt spall of enamel fragment which could not be convincingly matched up with any other teeth from the excavation. The same spit produced a deciduous upper incisor with Smith's (1984) wear stage 3, suggestive of a person who was between three and six years old at the time of death, depending on the rapidity of the rate of occlusal wear. Diameters are $4.5 \mathrm{~mm}$ (mesiodistal) and $3.85 \mathrm{~mm}$ (bucco-lingual), lingual shovelling is trace (ASU 1), but there is no labial 
shovelling, incisor interruption grooves, or signs of caries or macroscopic enamel hypoplasia. Tuberculum dentale development is moderate. The same person is probably represented by a deciduous right lower canine from Spit 35 with Smith's (1984) stage 2 wear. Mesio-distal and bucco-lingual diameters are $6 \mathrm{~mm}$ and $5.8 \mathrm{~mm}$ respectively, shovelling is absent, and no traces of caries or macroscopic enamel hypoplasia were observed. Both deciduous teeth would refer to a younger person than any of the permanent Nabulei Lisa teeth do, even though, as with most of the latter, they appear burnt.

A child of approximately seven to ten years of age at death is represented by two upper incisors with light occlusal wear and three unerupted premolars with incompletely formed roots. Even though wear is slightly greater on the right $\mathrm{I}^{2}$ (Smith 2) than the right $\mathrm{I}^{1}$ (Smith 1), and the latter alone shows the strong brown staining characteristic of the burnt and fractured cheek teeth, this would not provide sufficient grounds to assign them to separate individuals under a Minimum Number of Individuals model. Morphologically they are similar as both show slight lingual shovelling (ASU 3) and no interruption grooves. Additionally, neither displays any macroscopic enamel hypoplasia and although linear enamel hypoplasia (LEH) is discernible on the lower crown of both unerupted premolars represented by complete crowns, the latter would correspond to an arrest in enamel development after about five years old, by which stage the incisor crowns would have been completely formed (cf. Hillson 1996:144, 175). All four teeth with complete crowns are well preserved, in contrast to the typically fragmented status of the other permanent teeth from the site.

Table 8.2 gives details of provenance and crown diameters of the teeth of the seven to ten year old child. All of the mesio-distal diameters exceed the corresponding means of the largetoothed Walpiri males of central Australia, whereas all of the bucco-lingual diameters essentially match the respective mean values of Walpiri females (cf. Bulbeck 1981:29). The person's youthful status and lack of interstitial tooth wear explain the relatively big mesio-distal diameters, and so tooth size can be considered equivalent to that of central Australian females.

Table 8.2 Liang Nabulei Lisa: teeth assigned to a seven to ten-year-old

\begin{tabular}{|c|c|c|c|c|c|}
\hline \multirow[t]{2}{*}{ ТООТН } & \multirow[t]{2}{*}{ SPIT } & \multicolumn{2}{|c|}{ MAXIMUM CROWN DIAMETERS (MM) } & \multicolumn{2}{|c|}{ CERVICO-ENAMEL JUNCTION DIAMETERS (MM) } \\
\hline & & MESIO-DISTAL & BUCCO-LINGUAL & MESIO-DISTAL & BUCCO-LINGUAL \\
\hline Right I1 & 36 & 9.7 & 7.5 & 7.7 & 6.9 \\
\hline Right 12 & 35 & 7.8 & 6.5 & 5.9 & 6.4 \\
\hline P2 (side?) & 33 & 7.8 & 10.2 & 5.9 & 9.9 \\
\hline P occlusal fragment & 34 & & & & \\
\hline Right $P_{1}$ & 35 & 7.9 & 8.3 & 5.5 & 8.1 \\
\hline
\end{tabular}


The right $\mathrm{I}^{1}$ lacks any labial shovelling and has a medium tuberculum dentale, while the right $\mathrm{I}^{2}$ displays 'normal' development, trace labial shovelling (ASU 1) and a small tuberculum dentale. The upper premolar lacks any odontome or accessory marginal tubercle but displays marked accessory ridges on both the mesial and distal margins of the crown. The right $\mathrm{P}_{1}$ also has an accessory ridge (buccally) and no trace of an odontome, along with absence of any multiple lingual cusps (ASU 0).

The remaining teeth (see Table 8.3) were characterized by fracture lines along the enamel, which had often led to enamel fragments spalling off the crown, and other evidence of burning such as a brown, slightly shiny appearance. They could all well have come from the same adult person. We can be confident that the three second and third molars belong to the same person because the right $\mathrm{M}^{2}$ and $\mathrm{M}_{2}$ have perfectly matching occlusal surfaces, and the right $\mathrm{M}^{3}$ nestles neatly against the $\mathrm{M}^{2}$ along the margin that would have corresponded to their shared interstitial border. The occlusal wear on the teeth (see Table 8.3) is consistent with derivation from the same individual, as are other observations on them detailed below.

Linear enamel hypoplasia is macroscopically detectable only on the right $\mathrm{M}^{1}$ and $\mathrm{M}^{3}$ among the teeth and fragments considered here, in both cases on the cervical third of the crown. The two indicated interruptions to enamel growth would respectively correspond to developmental stages when:

1) only the occlusal quarter of the canines (in this case, subsequently lost through attrition) were being formed; and

2) after all the other tooth crowns had been completely formed (Hillson 1996:175).

Accordingly, we would not expect signs of linear enamel hypoplasia on the other teeth even if they had all come from the same person. Crown diameters can be measured only on:

1) the canines, with values similar to the averages for Walpiri males; and

2) the cheek teeth, with values more commensurate with the average diameters of Walpiri females and/or Melanesian, Bougainville Island males (cf. Bulbeck 1981:29).

Again, this finding is compatible with all of the teeth having come from the same individual.

A moderate degree (cf. Patterson 1984) of interproximal caries can be observed on the right lower canine from Spit 33, and the heavily worn upper premolar from Spit 36 has a small carious lesion low on its distal crown. The extant root of the premolar further bears a dark red stain, suggesting it had been exposed during life (stained during mastication) and, by inference, that the gums had experienced a considerable degree of resorption.

The canine from Spit 37 and canine fragment from Spit 35 both have trace (ASU 1) shovelling, whereas any shovelling is absent from the other two canines. The only other observable,

Table 8.3 Liang Nabulei Lisa: fractured teeth

\begin{tabular}{|c|c|c|c|c|c|c|}
\hline \multirow[t]{2}{*}{ ТООТН } & \multirow[t]{2}{*}{ SPIT } & \multirow[t]{2}{*}{$\begin{array}{c}\text { WEAR } \\
\text { (SMITH'S CLASSES) }\end{array}$} & \multicolumn{2}{|c|}{$\begin{array}{l}\text { MAXIMUM CROWN } \\
\text { DIAMETERS (MM) }\end{array}$} & \multicolumn{2}{|c|}{$\begin{array}{l}\text { CERVICO-ENAMEL JUNCTION } \\
\text { DIAMETERS (MM) }\end{array}$} \\
\hline & & & MESIO-DISTAL & BUCCO-LINGUAL & MESIO-DISTAL & BUCCO-LINGUAL \\
\hline Right I fragment & 34 & 4 & & & & \\
\hline Right lower C & 33 & 4 & $\geq 8.0$ & 8.5 & & \\
\hline C fragment & 35 & $?$ & & & & \\
\hline Right $\underline{C}$ & 35 & 4 & 8.5 & 9.0 & 6.2 & $\sim 8.8$ \\
\hline Left $\underline{C}$ fragment & 36 & 2 & & & & \\
\hline Left $\underline{c}$ & 37 & 5 & & & & \\
\hline P2 (?) & 36 & 6 & 6.8 & 10.1 & 5.2 & 8.4 \\
\hline$M_{1}$ (?) fragment & 36 & & & & & \\
\hline Right $M^{2}$ & 35 & 3 & 10.6 & 12.1 & 8.6 & 12.0 \\
\hline Right $M^{3}$ & 35 & 3 & 9.0 & 12.3 & 8.1 & 11.3 \\
\hline Right $M_{2}$ & 35 & 3 & 11.1 & & 10.3 & \\
\hline Right $M_{3}$ & 36 & 4 & $\geq 9.2$ & & & \\
\hline
\end{tabular}


canine morphological trait is the single-rooted condition of the Spit 37 canine. The upper premolar in Spit 36 is also single-rooted, this being its sole extant morphological trait. The right $\mathrm{M}^{1}$ displays a clear hypoconulid (ASU 4), a Y-groove pattern, a small (ASU 3) protostylid and two roots. The right $\mathrm{M}^{2}$ and $\mathrm{M}^{3}$ are both three-rooted and lack any parastyle, Carabelli's anomaly, or enamel extension. The $\mathrm{M}^{2}$ has a full hypocone (ASU 4) and the $\mathrm{M}^{3}$ preserves the trace of some degree of edge-tubercle development.

Scott and Turner (1997) present charts illustrating the frequency of expression of certain key morphological traits among Sino-American populations (divided here between Jomon and other Sino-Americans), Sunda-Pacific (Southeast Asian, Micronesian and Polynesian), and Sahul-Pacific populations. Five of their key traits may be observed on the Nabulei Lisa teeth (see Table 8.4). Although the incisor lingual shovelling would be more typical of Sino-Americans rather than any other circum-Pacific populations, the other expressions are more typical of Sunda-Pacific and Sahul-Pacific groups, and overall these would be the most likely affinities.

Table 8.4 Liang Nabulei Lisa: observed expressions on teeth in relation to circum-Pacific populations (after Scott and Turner 1997:(hapter 6)

\begin{tabular}{lcccc}
\hline MORPHOLOGICAL TRAIT & JOMON & SINO-AMERICAN & SUNDA-PACIFIC & SAHUL-PACIFIC \\
\hline I lingual shovelling ( $\geq$ ASU 3) & $+/-$ & + & $+/-$ & - \\
No I labial shovelling ( $\geq$ ASU 2) & + & $+/-$ & + & + \\
I lack interruption grooves & - & $+/-$ & + & + \\
4-cusped M2 & + & $+/-$ & + & + \\
Ms lack enamel extension & + & +- & $+/-$ & + \\
2-rooted M & + & $1+$ & $4+$ & $4+$ \\
Overall + or - & $3+$ & +- & + \\
\hline
\end{tabular}

$+=$ expression typical of the comparative populations

$+/-=$ ambiguous expression

- = expression atypical of the comparative populations

\section{Description of the Cranial Bone}

Cranial bone was recovered from Spits 23-39, and on anatomical grounds there would be no reason not to assign all fragments to the same individual. Most of the fragments join into a single partial skullcap (see Table 8.1) that starts at the frontal slightly anterior of bregma and the right coronal suture, which it crosses to incorporate much of the right upper parietal and a segment of the right lambdoid suture. An inferior parietal fragment that abuts the (open) temperomastoid suture, and a left supraorbital fragment, both from Spit 37, constitute two calvarial fragments that cannot be joined to the remainder of the skullcap. Spit 34 additionally yielded the zygomatic root of the right temporal bone, anteriorly as far as the zygotemporal suture (which is unfused), and from Spit 36 came the fragment of a malar bone near the zygomaxillary suture.

All sutures were unfused including at those locations along the coronal suture where the sutural teeth of adjoining frontal and parietal fragments could be slotted together (Fig. 8.1). Lack of suture closure would be consistent with a sub-adult status but on its own it is a very unreliable indicator (Brothwell 1981:43-5). Other observed traits would be consistent with a juvenile individual although an adult female status cannot be ruled out. The supraorbital fragment indicates a modest but distinct superciliary ridge, the malar fragment indicates minimal development of the malar tuberosity, while the temporal crest is 'slight' to the point of being indistinct on this specimen (cf. Larnach and Macintosh 1966:14, 16, 33). If the Nabulei Lisa adult teeth are female (and so would represent an individual with large teeth like those of Australian Aborigines) then they could be related to the partial cranium. 
No trace of a median frontal ridge was observed at the small portion of the extant frontal that crosses the midline. The parietal boss is 'slight', the obelionic depression is 'medium', there is no trace of an angular torus, and a parietal foramen is present as is a supraorbital foramen (cf. Larnach and Macintosh 1966:17, 19, 47, 52-3). No trace of cribra orbitalia could be observed on the tiny available portion of orbital roof.

Some of the frontal fragments, including those from Spits 32, 37 and 38, have lost the inner table, exposing the diploe on their endocranial aspect. Further evidence of post-depositional degradation of the endocranial surface comes from a set of interlinked, curvilinear indentations, inside of the obelionic depression, which are located too high on the vault to correspond to any middle meningeal artery vessels. These lines resemble root growth marks but may also reflect insect boring activity. The skullcap is remarkably thick in this region, measuring $8.2 \mathrm{~mm}$ near euryon, compared to $4.4 \mathrm{~mm}$ to $\sim 7 \mathrm{~mm}$ at other places on the parietal, and merely $4.6 \mathrm{~mm}$ on the frontal close to bregma. By the standards of Australian Aboriginal adults, we would expect the euryon and bregma thicknesses to be reversed, while by the standards of Aboriginal and Caucasian teenagers, we would expect thickness at euryon to vary between merely $2.6 \mathrm{~mm}$ and 4.4mm (cf. Brown et al. 1979:64-5). The exaggerated skull thickness at euryon is due to localised thickening of the diploe which measures $5.6 \mathrm{~mm}$ here, compared to a thickness about the same as that of the outer table wherever the cranial bone is thinner. However, pathological thickening through congenital thalassaemia (cf. Tayles 1997) would be an unlikely cause as the diploe lack the tell-tale 'hair on end' morphology, and the thickening appears localized. Most likely the euryonic thickening represents normal anatomical variation within the adult range of skull thicknesses.

\section{Description of the Postcranial Bone}

The postcranial material comprises a burnt femoral shaft fragment from Spit 23, and then from Spits 27-37, three pelvic fragments and ten phalanges which are unburnt and quite possibly represent the same person. The eight phalanges whose lengths could be measured or reasonably estimated (see Table 8.5) are consistently short by Australian male Aboriginal standards (Rao 1966:41-3, 108), but fairly average by male north Chinese standards (Von Bonin 1931, 1932), suggestive of derivation from the same individual. The phalanges would have reached their adult length because the epiphyses are fused in all cases with the relevant portion intact, but this need not imply an adult status because phalanx epiphyses can fuse during the teens as well as early adulthood (Brothwell 1981:66). However, if the phalanges came from the same person as the fragment of a left pubic symphysis in Spit 27, then an adult status would be indicated. Component I of the symphysis shows stage 1 development by male standards and stage 2 development by female standards, Component II corresponds to stage 2 whether male or female, and Component III shows stage 1 and stage 2 development by male and female standards respectively (cf. Brothwell 1981:69-70). If masculine the fragment would indicate an age at death of approximately

Table 8.5 Liang Nabulei Lisa: length of phalanges $(\mathrm{mm})$ and comparative male ranges

\begin{tabular}{llccc}
\hline SPIT & PHALANX & LENGTH & AUSTRALIAN RANGE & CHINESE MEAN AND RANGE \\
\hline 33 & Right 2nd manual distal & 16.2 & $16-23$ & $17.0(15-19)$ \\
34 & Left 2nd manual medial & 21.0 & $21-32$ & $22.5(18-27)$ \\
34 & Left 2nd manual distal & 16.6 & $16-23$ & $17.0(15-19)$ \\
34 & Left 5th manual medial & 16.1 & $17-24$ & $18.0(12-23)$ \\
34 & Right 1st pedal proximal & $\sim 30$ & $27-39$ & $28.0(20-34)$ \\
35 & Left 3rd manual distal & 15.6 & $16-22$ & $17.7(16-20)$ \\
35 & Right 5th manual distal & 15.5 & $15-20$ & $16.4(14-19)$ \\
36 & Right 1st manual proximal & 31.1 & $27-35$ & $28.9(26-33)$ \\
\hline
\end{tabular}


21 years, whereas if feminine, any age at death between 22 and 40 years old would be possible, with 30 a modal estimate.

The two phalanges whose length could not be reliably recorded are a left fifth proximal manual phalanx from Spit 34, and a left first proximal manual phalanx from Spit 36. Including the phalanges listed in Table 8.5, nine of the 10 recovered phalanges are manual, and one pedal. As well as the pubic fragment mentioned above, pelvic material includes a fragment $11.1 \mathrm{~mm}$ thick which ends at a crest and is tentatively identified as iliac crest (Spit 35), and a fragment from the left superior ramus of the pubis, which is suggestive of a small but robust ramus (Spit 37). Finally, the femoral fragment from Spit 23, made up of three conjoining fragments, has small development of the pilaster and thin cortical bone, and would more likely be female or sub-adult than adult male.

\section{Conclusions}

The two youngest individuals from Liang Nabulei Lisa, who had died at about 3-6 and 7-10 years of age, are represented only by their teeth. The teeth further demonstrate the presence of at least one adult, but this individual's relation to the extant bone is not clear. On balance, the most parsimonious assignment would relate the adult teeth, the partial cranium, the pelvic and femoral fragments and the phalanges to a female adult. This woman would have died between 22 and 40 years of age, and could well have had tooth and phalanx dimensions similar to those of recent Australian Aborigines. Nonetheless, the partial calvarium, the phalanges and/or the femoral fragment could - any or all of them - relate to a teenager.

However these osteological skerricks might be assigned, there is minimal evidence of any stratigraphic ordering in their representation. The younger child is confined to Spits 29-35, and the older child to Spits 33-36, whereas remains of the adult (assuming most material belongs to it) would range from Spits 23-39. If we look at represented parts of the skeleton, although cranium tended to be found lower than teeth and especially postcranial bone (see Table 8.1), there is extensive overlap (e.g. cranium between Spits 23 and 39, teeth and fragments between Spits 29 and 41, and postcranial remains between Spits 23 and 36). Essentially, the greater the number of fragments there are that should be assigned to any individual or to any part of the skeleton, the wider the dispersal of those fragments in the excavated deposit.

The commingling of fragments from at least three persons, the variation among the represented elements from a partial skullcap to bones as small as phalanges, the lack of evidence for stratigraphic ordering of the remains, and the indications of burning of the teeth and the femoral fragment, are all consistent with secondary burial. A scenario of at least two burial events would help account for the considerable vertical dispersion of the fragments but other scenarios would also suffice to explain the point. The fragments start in earnest at Spit 32 and continue unabated till Spit 39, so it would seem that the cavity made to receive these remains had been dug from a higher level than Spit 32 and had bottomed out at Spit 39. The fragment of enamel in Spit 41 could be easily accounted for through post-depositional infiltration, while scuffage and post-burial upward movement could account for the presence of fragments as high as Spit 23.

\section{Acknowledgements}

Professor Colin Groves provided sound advice on interpreting the endocranial morphology. 


\section{References}

von Bonin, G. 1931. Preliminary study of the northern Chinese hand. Anthropologischer Anzeiger 7:241-56.

von Bonin, G. 1932. Preliminary study of the northern Chinese foot. Anthropologischer Anzeiger 9:214-27.

Brothwell, D.R. 1981. Digging up Bones. Third edition. Oxford: British Museum (Natural History)/Oxford University Press.

Brown, T., S.K. Pinkerton, and W. Lambert. 1979. Thickness of the cranial vault in Australian Aboriginals. Archaeology and Physical Anthropology in Oceania 14:54-71.

Bulbeck, F.D. 1981. Continuities in Southeast Asian Evolution Since the Late Pleistocene. Unpublished M.A. thesis, Department of Archaeology and Anthropology, Australian National University, Canberra.

Hillson, S. 1996. Dental Anthropology. Cambridge: Cambridge University Press.

Howells, W.W. 1989. Skull Shapes and the Map. Cambridge, Mass.: Harvard University Press.

Larnach, S.L. and N.W.G. Macintosh. 1966. The Craniology of the Aborigines of Coastal New South Wales. Sydney: University of Sydney. Oceania Monographs 13.

Martin, R. and K. Saller. 1957. Lehrbuch der Anthropologie. Fifth edition. Stuttgart: Gustav Fischer Verlag.

Patterson, D.K. jr. 1984. A Diachronic Study of Dental Paleopathology and Attritional Status of Prehistoric Ontario PreIriquois and Iriquois Populations. Ottawa: National Museum of Canada.

Rao, P.D.P. 1966. The Anatomy of the Distal Limb Segments of the Aboriginal Skeleton. Unpublished PhD thesis, Department of Anatomy, University of Adelaide, Adelaide.

Scott, G.R. and C.G. Turner II. 1997. The Anthropology of Modern Human Teeth. Cambridge: Cambridge University Press.

Smith, B.H. 1984. Patterns of molar wear in hunter-gatherers and agriculturalists. American Journal of Physical Anthropology 63:39-56.

Tayles, N. 1997. Anemia, genetic diseases, and malaria in prehistoric mainland Southeast Asia. American Journal of Physical Anthropology 101:11-27. 